\title{
Variation by Geographic Scale in the Migration-Environment Association: Evidence from Rural South Africa
}

\author{
Lori M. Hunter, Stefan Leyk, Galen J. Maclaurin, Raphael Nawrotzki, \\ Wayne Twine, Barend F.N. Erasmus, Mark Collinson
}

\begin{abstract}
Scholarly understanding of human migration's environmental dimensions has greatly advanced in the past several years, motivated in large part by public and policy dialogue around "climate migrants". The research presented here advances current demographic scholarship both through its substantive interpretations and conclusions, as well as its methodological approach. We examine temporary rural South African outmigration as related to household-level availability of proximate natural resources. Such "natural capital" is central to livelihoods in the region, both for sustenance and as materials for market-bound products. The results demonstrate that the association between local environmental resource availability and outmigration is, in general, positive: households with higher levels of proximate natural capital are more likely to engage in temporary migration. In this way, the general findings support the "environmental surplus" hypothesis that resource security provides a foundation from which households can invest in migration as a livelihood strategy. Such insight stands in contrast to popular dialogue, which tends to view migration as a last resort undertaken only by the most vulnerable households. As another important insight, our findings demonstrate important spatial variation, complicating attempts to generalize migration-environment findings across spatial scales. In our rural South African study site, the positive association between migration and proximate resources is actually highly localized, varying from strongly positive in some villages to strongly negative in others. We explore the socio-demographic factors underlying this "operational scale sensitivity". The cross-scale methodologies applied here offer nuance unavailable within more commonly used global regression models, although also introducing complexity that complicates story-telling and inhibits generalizability.
\end{abstract}

Keywords: Migration · Climate - Environment · Natural resources · Livelihoods · South Africa $\cdot$ Scale $\cdot$ Operational scale sensitivity 


\section{Introduction}

Scholarly understanding of human migration's environmental dimensions has greatly advanced in the past several years, largely in response to public and policy dialogue about "climate refugees". As Gray and Bilsborrow (2013) have noted, the more public "conventional narrative" of millions of climate-driven international migrants misses the mark; most research places environmental drivers among a host of other forces shaping migration, with environmentally induced migration tending to cover shorter distances and remaining within national borders (e.g., Beine/Parsons 2015; Gray/Mueller 2012a/b). In this way, migration can be seen as an adaptive livelihood strategy used historically by human populations responding to environmental shifts (e.g., McLeman 2013a). Even so, given the rising political tensions surrounding migration, understanding its determinants is particularly timely.

The research presented here on the migration-environment connection offers both new interpretations and a geographically refined and nuanced analytical approach. We examine temporary outmigration in the Agincourt Health and Demographic Surveillance site in rural South Africa, especially as related to householdlevel availability of proximate natural resources. This "natural capital" is central to livelihoods in the region, both for sustenance and as input for market-bound products (e.g., Thondhlana et al. 2012). But beyond this paper's overall examination of the migration-environment connection in this context, we also contrast the results across spatial scales demonstrating the importance of considering both regional and more localized patterns.

In general, our results align with the "environmental surplus" hypothesis that contends temporary livelihood migration is more likely when households have relatively secure access to environmental assets such as natural resources or productive agricultural land. In this way, livelihood security may fuel temporary migration in pursuit of labor diversification. This association contrasts with that of the "environmental scarcity" hypothesis which would alternatively contend that temporary migration occurs more often in times and places characterized by resource strain. In this way, our results counter the popular narrative of environmentally-induced migration by the most vulnerable households.

Yet beyond our general results in support of an "environmental surplus" fueling temporary migration, our findings also demonstrate that the association between environmental factors and outmigration is highly localized - in our study setting, the association varies across neighboring rural villages. We characterize this empirically as "operational scale sensitivity" since the process under examination "operates" at the household scale where temporary migration decisions are made, yet the statistical significance of various predictors is sensitive to analytical scale (Maclaurin et al. 2015).

The paper proceeds as follows. We first offer an overview of recent research on the migration-environment connection, followed by the presentation of our specific research objectives. We next describe the rural South African research setting as well as our data and analytical approach. The results are presented in two phases - first, the findings of global models are reviewed which represent results 
of models estimating temporary migration for the Agincourt study site as a whole. This is followed by the presentation of the findings when estimated for each village individually, including overall environmental effects on temporary migration as well as interactions which explore variation in these effects according to key household characteristics. We conclude with a discussion of the overall substantive contributions of the work along with a discussion of methodological implications of operational scale sensitivity. Overall, we argue that the methodological framework applied here offers more detailed insight than available through global regression models. Even so, the complexity introduced also complicates interpretation and inhibits generalizability regarding the environmental dimensions of temporary migration.

\section{Environmental Dimensions of Migration}

Population scholars have long explored the socioeconomic dimensions of migration, but the contemporary era of climate change has brought increasing research attention to migration's environmental aspects (e.g., Hunter et al. 2015). A wide variety of empirical case studies have emerged offering important theoretical and methodological advancements (e.g., Aksakal/Schmidt 2015; Nawrotzki et al. 2015; Thiede et al. 2016). Also, recent research syntheses offer summary lessons (e.g. Hunter et al. 2015; McLeman 2013a), with most studies finding that environmental factors do indeed affect migration - although in different ways across settings and through interactions with economic, political, and cultural forces (e.g., Black et al. 2011).

As the literature on migration-environment connections has emerged and become more sophisticated, theoretical perspectives have also become more refined. "Maximalists" argued that environmental factors exhibited a strong and direct causal link with migration. This perspective generally predicted millions of "climate refugees" (Myers 2002). In contrast, the "minimalist" perspective provided more nuance - with environmental factors interacting with political, economic, and cultural processes to shape migration patterns (e.g. Morrissey 2012; the "maximalist" vs. "minimalist" debate is outlined by Suhrke 1994). Migration theory, such as the New Economics of Labor Migration perspective (NELM), have proven useful in working through this debate. NELM argues that temporary migration in particular is often used by households as a strategy to diversify livelihoods by spreading risk through engagement in geographically distinct labor markets (Stark/B/oom 1985). Although not developed explicitly for research on the environmental aspects of temporary migration, NELM has proven useful in examining migration, particularly for households in regions vulnerable to environmental strain and environmental change, since temporary migration can spread environmental risk through movement to areas with different risk profiles (e.g. Nawrotzki et al. 2015).

The NELM introduces another important consideration in migration-environment research - the utility of a regional perspective. This argument has recently been made by Hillmann and colleagues (2015: 2) in a collection presenting the "region" 
as the "place where the local, the national and the global scales meet". The research presented here illustrates their emphasis on "bottom up" perspectives through its explicit consideration of spatial variation.

Other perspectives beyond migration theory have also proven useful in disentangling environmental effects, including the Sustainable Livelihoods Framework (SLF). The SLF outlines the variety of assets (i.e. "capitals") households have at their disposal for the development of livelihood strategies (e.g. temporary migration) intended to reach particular livelihood goals (e.g. food security). The assets include human, financial, social, and physical capital, while SLA also integrates natural capital or elements of the local environment that households use toward livelihood goals (Scoones 1998, 2009). The central integration of natural capital into livelihood theory is especially useful when examining temporary migration strategies for natural resource-dependent households. Our research team has long made use of this framework in the Agincourt context (e.g. Hunter et al. 2007; Hunter et al. 2014; Leyk et al. 2012).

Using these theoretical perspectives and a wide variety of environmental measures, quantitative migration-environment research has been undertaken in a wide variety of settings across the globe (Bilsborrow 2009). Examples of such measures include rainfall and temperature patterns (e.g., Gray/Wise 2016; Nawrotzki/DeWaard 2016), vegetation coverage (Hunter et al. 2014), and indicators of environmental extremes such as flooding (Gray/Mueller 2012a). In addition, qualitative case studies have examined the environmental dimensions of migration in "hotspots" including Egypt, Mozambique, and Vietnam (Warner 2011). Several methodological overviews have also been published, which offer, for example, descriptions of applications of survey research, use of secondary data, and different data sources used to reflect environmental conditions and change (e.g., Fussell et al. 2014; Kniveton et al. 2008; McLeman 2013b; Piguet 2010).

All in all, several key findings are emerging from the myriad migration-environment studies undertaken over the past two decades. First, much environment-associated temporary migration is domestic, short-term, and often cyclical. In Burkina Faso, for example, rain-fed agriculture is a dominant livelihood strategy, although a south-north rainfall gradient, combined with poor soils, limits the long-term viability of agricultural livelihoods, particularly in the nation's north. Residents of relatively dry regions are generally more likely to migrate, but short-term rainfall deficits and harvest failures limit households' ability to invest in long-distance moves. Rather, short-distance, cyclical temporary migration is a common strategy in times of environmental stress (Henry et al. 2004). Similar findings emerge in other settings, including several nations in South Asia (Bhatta/Aggarwal 2016). Such migration may be seen as aligned with the "environmental scarcity" hypothesis, which argues that households are more likely to engage in temporary migration as a strategy during environmentally stressful times. In Ghana, north-south migration has been linked to land scarcity in sending regions - another example of "environmental scarcity," although regional structural differences in economic opportunities also act as an important pull factor for internal migrants (Van Geest 2011). Outside of Ghana, research reveals similar support for "environmental scarcity" in a number of settings 
as varied as Mexico (Nawrotzki et al. 2015), Bangladesh (Etzold et al. 2014) and Pakistan (Mueller et al. 2014).

Second, longer-distance temporary migration, often (but not always) across international borders, tends to be associated with heightened resource availability, likely reflecting the cost of such migration. This finding has been demonstrated in the research on Burkina Faso reviewed above, as well as in rural Ecuador, where land provides capital that can facilitate longer-term temporary migration (Gray 2010). Although such findings are less common than "environmental scarcity," they align with the "environmental surplus" hypothesis which argues that households are more likely to engage temporary migration as a livelihood diversification strategy when acting from a foundation of relative security. A different pattern emerges in Mexico, however, where rainfall shortages predict international, but not internal, migration - although research suggests that this distinction is related to the existence of long-running migration networks between Mexico and the U.S. (Nawrotzki et al. 2016).

Third, several studies have illustrated gendered distinctions in the migrationenvironment association. Of course, migration - as a social process - is clearly a gendered phenomenon in general (Hunter/David 2011; Debnath 2015). In rural Ecuador, for instance, age and education tend to predict male temporary migration streams, but female streams are more likely to be permanent and associated with changes in family structure (i.e., marriage) (Barbieri/Carr 2005). Migration streams are also shaped by gendered norms regarding participation in agriculture, which is in turn linked to environmental factors. Again in rural Ecuador, access to agricultural land facilitates international migration for men, but not women - poor agricultural productivity tends to keep women at home (Gray 2010).

Fourth, as with migration in general, a key factor shaping migration-environment linkages is the existence of migrant social networks (Nawrotzki et al. 2015). In Mexi$\mathrm{co}$, as noted, short-term rainfall deficits are associated with international, temporary migration from rural villages, but only from regions with long-standing Mexico-U.S. migration networks (Hunter et al. 2013). Finally, while environmental factors play a discernible role in migration, particularly from rural regions, there are also close interactions with political, economic, and cultural forces that need to be taken into account (Black et al. 2011, and references therein).

This informative collection of new research findings could not have been possible without substantial methodological innovation. For example, migration-environment researchers have been quick to integrate advancements in multilevel modeling (e.g., Nawrotzki e al. 2012), and to explore the utility of approaches such as Agent-Based Modeling ( $A B M)$. In fact, some researchers have used ABM and sociodemographic correlates of migration to simulate streams as far forward as 2045 (Kniveton et al. 2012). Even so, spatial methodologies represent an important approach that remains under-represented in migration-environment scholarship. Such approaches are essential as migration-environment researchers aim to "put people in place" (Entwisle 2007: 687).

Spatially-refined analytical approaches are particularly relevant to this area of study because while political and economic forces clearly shape broader migration 
probabilities and directions, environmental influences and forces are likely even more strongly localized, especially in areas where residents are highly dependent on proximate resources. In our South African study setting, for example, villagers rely heavily on the productivity of bordering communal landscapes for fuelwood and sustenance. In such areas, regressions reflecting average associations across the entire study setting may mask localized associations (e.g., Leyk et al. 2012). Such may be the case with a broad regional perspective as well and, as such, attention must be paid to the scale at which the processes under study operate.

This concern can be situated more generally in the dialogue regarding global and local modeling approaches (e.g. Fotheringham 1997; Fotheringham/Brundson 1999; Leyk et al. 2012). Our models reflecting all Agincourt households combined - the "global models" - seek to identify regularities across the setting as a whole. In contrast, village-scale estimates - the "local models" - demonstrate differences across space (Fotheringham 1997). The difference between global and local model results illustrate the impact of decisions regarding geographic scale - impacts related to the boundaries used to define the importance of the location, as well as the size and extent of the population in question. We distinguish the geographic scale from the scale at which the processes under study actually unfold - the operational scale - and describe this as "operational scale sensitivity".

The methodological concern demonstrated here is distinct from, but related to, both the ecological fallacy and the modifiable areal unit problem (MAUP). The ecological fallacy is well known among human ecology scholars, arising from making conclusions regarding individual or household-level processes based on the analysis of aggregate units (Robinson 1950; Waller/Gotway 2004). The interpretive leap is problematic due both to potential confounding effects not represented at the aggregate scale, as well as aggregation bias where model associations could shift and thus provide a very different picture of the process of interest (e.g., Greeland/ Morgenstern 1989). Similarly, the more geographic perspective on the ecological fallacy - called the modifiable areal unit problem (Openshaw 1983) - also takes into consideration that analyzing aggregate data can yield differing conclusions depending on the level of this aggregation. More specifically, the MAUP entails two subproblems: (1) the scale effect suggests that results will differ when analyzing the same data at different aggregation levels, and (2) the zoning effect suggests that the form or shape in which spatial analysis units are aggregated will produce different results (Wong 1995).

In the migration context, recent research on the MAUP effect examines the performance of different predictive variables in models of varying aggregation. This concept - termed operational scale sensitivity (OSS) - provides a framework for the examination of how model associations change with increasing levels of aggregation (when the analytical scale departs from the operational scale which in the case of temporary migration decisions is often made at the household level) (Maclaurin et al. 2015).

Within the analyses presented here, the analytical focus remains at the household level - the appropriate operational scale given that migration represents a household-level decision in the rural South African setting. Yet we alter the geo- 
graphic scale and thus the spatial extent or population size at which the models are estimated (Lam/Quattrochi 1992). Differences in household-level analysis results across different population sizes raise the issue of sensitivity where the explanatory power of certain variables depends on the spatial extent or population size for which the statistical relationship of interest is estimated.

\subsection{Research Objectives}

This project adds both nuance to substantive understanding of migration-environment connections while also emphasizing caution regarding generalization when analyzing this association. The recommended caution results from the distinctions between the outcomes of "global" and "local" models within our exploration of operational scale sensitivity.

Our specific objectives were to (1) identify the overall "global" association between temporary migration and proximate natural resource availability in our rural South African study site; (2) explore variation in this association across "local" models (i.e., for individual villages); and (3) identify household characteristics that differentially shape the migration-environment association at each geographic scale.

\subsection{Research Setting}

The study site - situated in the far northeast of South Africa - is that of the Agincourt Health and Socio-Demographic Surveillance System (Agincourt HDSS), operated by the Rural Public Health and Health Transitions Research Unit (Agincourt Unit) of the South African Medical Research Council (MRC) and University of the Witwatersrand (Wits) (Fig. 1). The $450 \mathrm{sq}$. $\mathrm{km}$. area encompasses 31 villages, home to approximately 110,000 residents in 18,000 households. Since 1992, the Agincourt Unit has conducted an annual census, including the collection of migration information, in the entire Agincourt HDSS population.

A "homeland" area for black South Africans during the era of apartheid, the study site is characterized by high population densities ( $\sim 170$ persons per sq. $\mathrm{km})$, high poverty, and a longstanding lack of development and access to state services. Two paved roads, one north-south and the other east-west, provide access to nearby mid-sized cities. The study site's eastern border is fenced by private game reserves that themselves border world-renowned Kruger National Park, famous for wildlife tourism.

The Agincourt study site's settlement pattern is fairly typical of rural communities across South Africa, and socioeconomically it is characterized by a high reliance on remittances from the large proportion of adults who are migrant laborers on commercial farms and in towns and cities across the country. A substantial portion of households also depend heavily on the state pensions of elderly members ( $\mathrm{Co}$ linson 2010).

The area is generally dry (annual rainfall of $550-700 \mathrm{~mm}$ ), although an east-west rainfall gradient shapes locally varying resource availability. Household plots are typically too small to fully support subsistence agriculture; some households farm 
Fig. 1: Study Area, Agincourt Health and Demographic Surveillance Site, Mpumalanga Province, South Africa

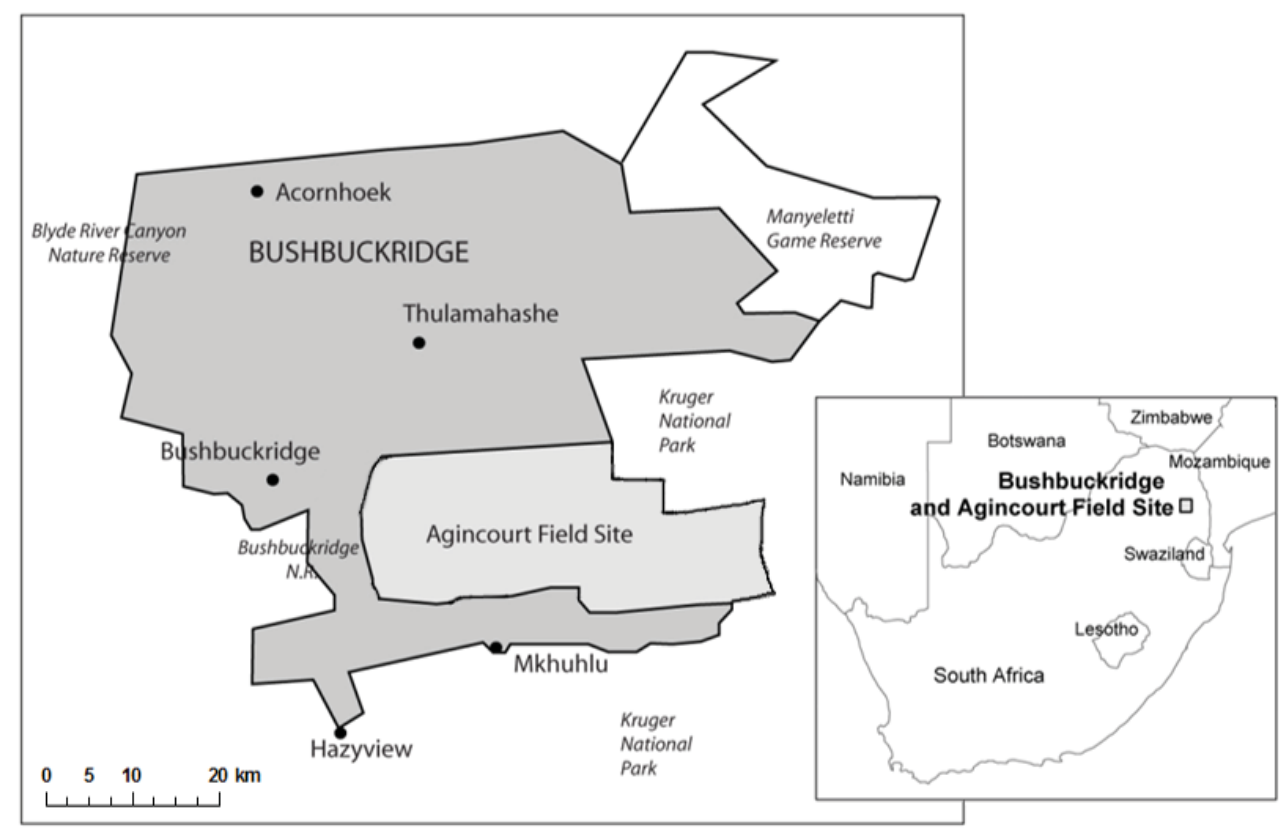

Source: own design

assigned plots in the surrounding communal lands. Residents are typically quite dependent on the natural environment for a range of uses, including grazing livestock and collecting fuelwood, wild foods, thatching grass, construction timber, and other domestic products both for household consumption and for generating income (Shackleton/Shackleton 2000).

\section{$3 \quad$ Data}

In the South African context, a household can be loosely defined as "a group of people living on the same property who eat from the same pot of food" (Madhavan et al. 2009: 39). In many rural regions of developing areas, including the Agincourt study site, such households - which often include extended kinship networks act as the primary unit of production and consumption, reaching decisions regarding livelihood activities based on household needs. Migration represents one such livelihood decision. Indeed, in rural South Africa, migration decision-making occurs primarily at the household level, as opposed to representing a decision made solely by an individual (Cohen 2004; Collinson et al. 2006; Taylor 1999). As such, the household is our analytical unit, and all variables are aggregated to this level. In some cases, we use information about the household head as representative of the 
larger household unit, since the household head often dominates decision-making about livelihood strategies.

We use demographic data from the Agincourt Health and Demographic Surveillance System (Agincourt HDSS) for the year 2007. For this year, the sample comprised 9,625 households located in 21 villages (see Fig. 2). ${ }^{1}$ The Agincourt HDSS dataset includes geo-referenced location information for each household, allowing information about the availability of natural resources to be appended through a Geographical Information System (GIS). Details are given below.

Fig. 2: Village Names and Identifying Numbers, Agincourt Health and Demographic Surveillance Site, Mpumalanga Province, South Africa

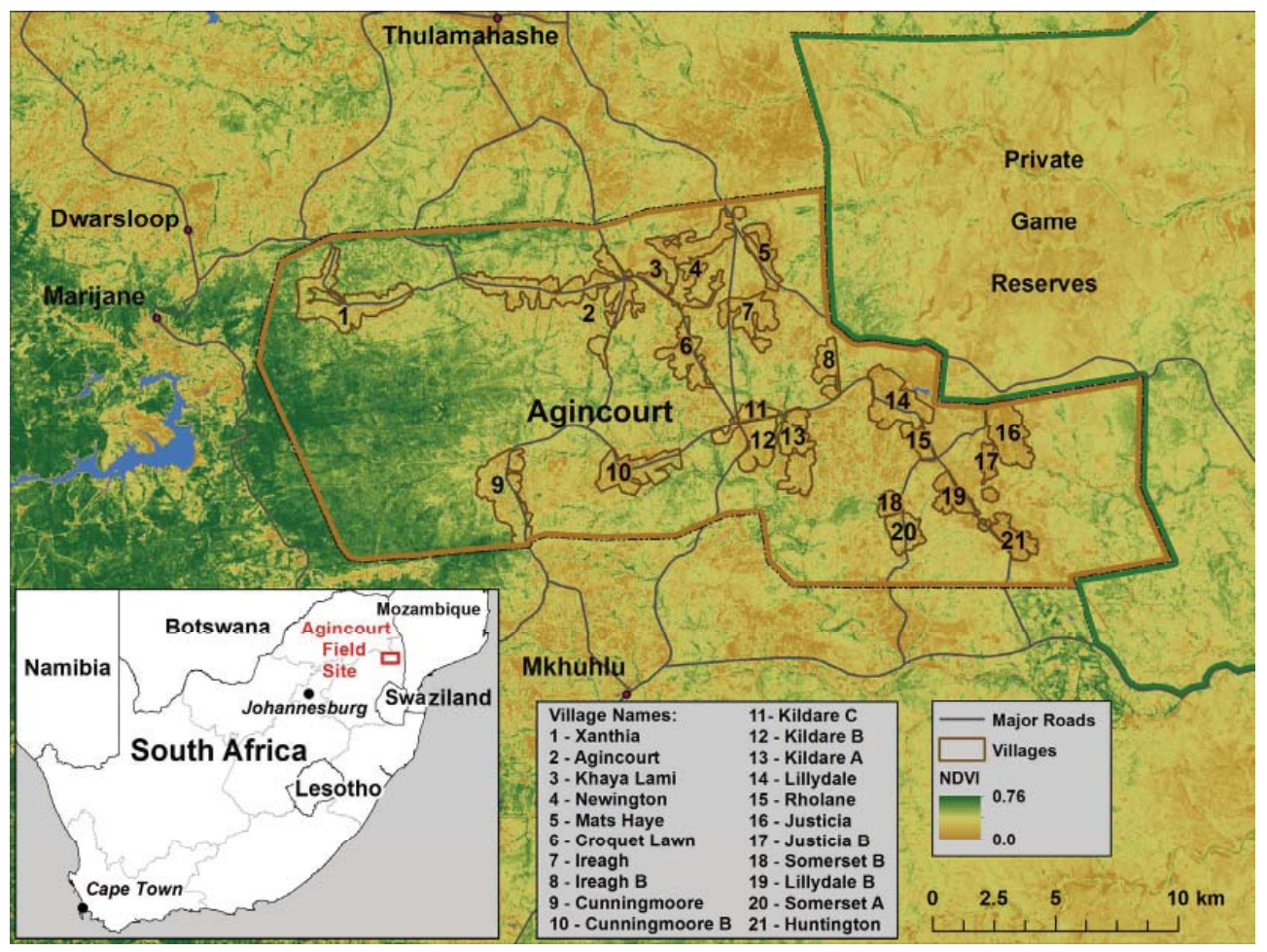

Source: own design

1 The Agincourt HDSS site has expanded geographically and now includes 31 villages, although we make use only of 21 villages that have been included in the study site for much of its history. 


\subsection{Dependent Variable}

A measure of temporary migration represents our dependent variable. Temporary migration is a well-established phenomenon with a long tradition in Agincourt (see Tollman et al. 1999), with 60 percent of men and 14 percent of women aged 30-49 years recorded as migrants each year (Collinson et al. 2006). In this way, the region can be said to have a "culture of migration" as has been identified in Mexico (Kandel/Massey 2002). Our measure of temporary migration status is based on "resident months," which record the amount of time each person is physically present in the household during the year preceding the census interview. In the Agincourt context, a temporary migrant is defined as a household member who is away for more than 6 months in that year but retains a livelihood connection (e.g. through remittances) to the sending household (Agincourt HDSS 2011; Collinson 2010). ${ }^{2}$

We consider only the temporary migration of adults (age 15+), since we are interested in livelihood migration, which is predominantly labor-related. For modeling purposes, instead of dichotomizing the variable to represent migrant vs. nonmigrant households, we employ a count measure allowing for the maximum use of information available within the data, a common strategy in migration research (Bohara/Krieg 1996; Leyk et al. 2012). Descriptive statistics can be found in Table 1, demonstrating that across Agincourt, households had 1.2 temporary migrants on average in 2007, with a range of 0 to $12 .^{3}$

\subsection{Independent Variables}

\subsubsection{Primary Predictor}

The environmental data were derived from Moderate Resolution Imaging Spectroradiometer (MODIS) remote sensing imagery (http://modis.gsfc.nasa.gov) provided by the National Aeronautics and Space Administration (NASA), and locally processed by the Institute for Soil, Climate and Water (ISCW) of South Africa's Agricultural Research Council (ARC). Our primary predictor reflects a satellite-derived index indicating the availability, and recent changes in the availability, of proximate natural resources. The normalized difference vegetation index (NDVI) is one of a number of commonly used indicators that enable the evaluation of environmental change's impact on vegetation greenness (Roerink et al. 2003; Wang et al. 2003;

2 Agincourt HDSS employs a de jure household definition that retains links between temporary migrants and their rural household (Collinson 2010).

3 It is important to acknowledge that our analytical focus on temporary migration neglects considerations of permanent movement out of the Agincourt study area. In fact, our use of data from only the 2007 round of the Agincourt annual census precludes consideration of permanent migration of full households since they would not be observable. Even so, as noted, temporary migration, taken as a household livelihood decision, is a common phenomenon within this context (Collinson et al. 2006) and most aligns with research in other settings on the environmental correlates of migration processes and patterns. 
Zhou et al. 2003). Chlorophyll absorbs red light and the mesophyll tissues in plants scatter near infrared light; the NDVI is the difference between the values in the red and near-infrared spectral bands divided by the sum of these same values (Tucker 1979). This ratio has a theoretical range from -1 to 1 , with negative values indicating senescent or dead vegetation. Positive values reflect actively growing green vegetation. NDVI values saturate at high biomass (Huete et al. 2002), but preliminary field work shows that Agincourt, which falls in a semiarid savanna region, does not contain areas with high enough biomass to approach this saturation point. Thus, NDVI can be used as an effective proxy for vegetation cover in this region. Tree biomass (e.g., fuelwood) and non-timber productivity (e.g., seed production, stem growth) are also positively correlated with NDVI (Foody et al. 2001; Mutanga/Skidmore 2004a/b; Wang et al. 2004). Therefore, this greenness proxy effectively maps the availability of natural resources used directly by Agincourt residents (fuelwood, wild foods). NDVI has also been successfully employed in livelihood-focused studies of the environment-migration association elsewhere in southern Africa (Nawrotzki et al. 2012).

We created NDVI grids for the years $2005-2007$ by calculating the annual NDVI mean of 16-day composites obtained from MODIS satellite imagery (250-meter resolution). To reflect more general patterns of resource availability during this period, we take the average of these three grids at each pixel to produce a greenness grid. We then generated 2-kilometer buffers around each household, as this represents a maximum typical walking distance for natural resource collection in this region (cf. Fisher et al. 2011; Giannecchini et al. 2007). We excluded productive areas within village boundaries, since these are typically private homestead gardens unavailable for communal collection. To generate a single measure of available natural resources, we then calculated the sum of all pixels from the greenness grid outside the village boundaries and inside the 2-kilometer buffer for each household. The number of pixels representing communal land varies across households, thus the sum (rather than the mean) is calculated. This difference in pixels reflects, in a substantive sense, the ease with which households can access communal lands. Households with fewer pixels within their 2-kilometer buffer will need to travel further for the same access as a household on a village edge and, therefore, with more communal landscape available within their 2-kilometer buffer. Finally, the measure was scaled to the range of NDVI. The "NDVI mean" variable represents our central measure of natural resource availability.

As noted above, a clear west-east rainfall gradient shapes spatial variation in natural capital. Villages in the northwest are surrounded by communal lands with the densest vegetation cover - in Figure 2, see Xanthia and Agincourt (the village from which the study site took its name). However, the communal landscapes surrounding eastern villages receive less rainfall and therefore are less productive, while also experiencing higher collection pressures given the higher concentration of villages. 


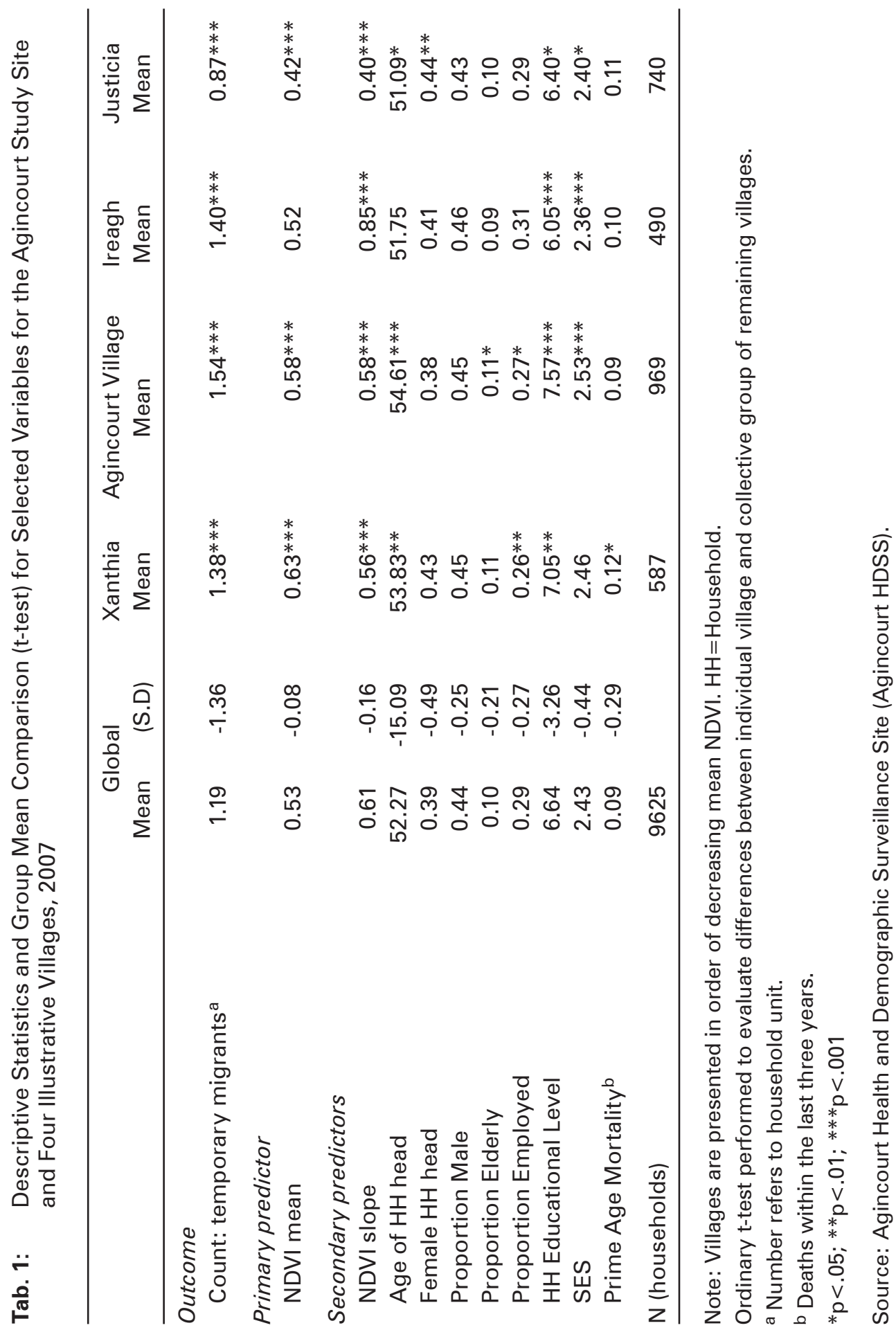




\subsubsection{Secondary Predictors (Control Variables)}

A host of sociodemographic variables that are known determinants of migration (White/Lindstrom 2006) represent a variety of livelihood capitals and serve as controls. ${ }^{4,5}$ Beyond being controls, however, these sociodemographic variables also serve as secondary predictors of substantive interest. We use interaction terms in statistical models to shed light on the types of households most likely to demonstrate significant migration-environment connections at both global and local geographic scales. Additional detail is provided in the methods section below.

Human capital. Arguably the most important measure of human capital is educational attainment (Saenz/Morales 2006), which generally exhibits a positive association with migration. To capture the overall household educational level, we include a per capita measure of years of schooling, considering only adult household members (age 15+).

A household's stage in the life cycle also shapes the likelihood of migration (Nivalainen 2004; White/Lindstrom 2006) as well as the level and patterns of natural capital use (De Sherbinin et al. 2008; Vanwey et al. 2007). In line with previous research, we use the household head's age to capture differences in life-cycle stage (Edmeades 2008; Carr et al. 2006). A third measure of human capital is elder dependency proportion: the percentage of adult household members age 65 and above. Elder dependency may shape migration probabilities in two ways: (1) by decreasing household potential to engage in the labor force (Juelich 2011) and (2) by enhancing financial security through state-funded pensions, small but stable sources of income in South Africa (Collinson 2010).

Research also frequently finds substantial gender differences in the environment-migration association (Henry et al. 2004; Gray 2010; Gray/Mueller 2012b). In Agincourt, males have a tradition of labor migration and are more likely to be the primary household breadwinners, but young women are increasingly migrating to pursue opportunities and gain freedom from traditional rural society (Collinson 2010). We incorporate two measures to examine gender effects: (1) a dichotomous

4 Within the Agincourt HDSS, different modules are fielded annually, so that some information is collected only every second, third, or fourth year. Consequently, we use some data collected before our study year as proxies. For example, educational data collected in 2006 were used in the 2007 models, as was labor status information from 2004.

5 In preliminary analyses we included marital status and Mozambican background in the estimations. They are not, however, included in the final presentation for the following reasons. Marital status was represented by a set of dummy variables (married 53 percent, divorced 12 percent, widowed 18 percent and missing 17 percent). Except for the missing category, there was no evidence for differences in temporary migration based on marital status. On ethnicity, during the 1990s, Agincourt experienced a high influx of refugees from neighboring Mozambique as a result of the 1983-1992 Mozambique civil war (Hargreaves et al. 2004; Madhavan et al. 2009). In our sample, 27 percent of households are headed by individuals of Mozambican background. Although citizenship was made available to refugees in 1996, this remains a marginalized population, as social and cultural barriers prevent equal access to resources (Collinson 2010). However, owing to a high level of segregation (two villages are composed almost entirely of households of Mozambican background), this variable lacks the necessary variation to be included. 
measure for the gender of the household head ( $1=$ female) (in Agincourt, poorer female-headed households send migrants as a means of escaping poverty; see Collinson 2010), and (2) a masculinity proportion, which captures the overall gender composition of adult household members.

Finally, an important factor shaping household human capital and livelihood strategies in the study area is prime age adult mortality due to the HIV/AIDS pandemic (e.g., Hunter et al. 2011). A dummy variable indicates whether the household experienced the death of an adult aged 15-49 in the past three years.

Financial and physical capital. Classic migration frameworks stress the importance of income differentials, relative deprivation, and living conditions as important migration motivators (Massey et al. 1993). In Agincourt, these aspects of socioeconomic status, encompassing both financial and physical livelihood capitals, are most usefully reflected through an asset index (Agincourt HDSS 2011; Mberu 2006). As in rural regions of many developing areas, income is challenging to measure because there is a significant informal economy and much employment is seasonal (Montgomery et al. 2000). To measure socioeconomic status (SES) more generally, the Agincourt HDSS collects data on five categories of physical capital: modern assets (e.g., cell phones, refrigerators, televisions); livestock (e.g., cattle, goats, pigs); power supply (e.g., electricity, gas, fuelwood); water and sanitation (e.g., toilet type, private water supply); and dwelling structure (e.g., roof and floor material, number of rooms). ${ }^{6}$ We anticipate a positive association between household temporary migration and SES, as has been shown in recent Agincourt-based scholarship (Co/linson 2010). Better-off households can more likely afford the costs of migration and may have destination connections that facilitate relocation and/or employment. In turn, migrant remittances reinforce the higher socioeconomic status of migrantsending households (Taylor et al. 1996).

Of course, socioeconomic status is clearly associated with employment status, so we include a measure of the proportion of adult household members employed in 2007. Agincourt residents tend to be employed locally, primarily in the public sector (teaching, clerical work, or police work) or in the informal sector (selling fruit, cooked food, and snacks) (Collinson 2010). However, residents may also seek employment outside the study area, predominantly in the tourism sector (Binns/Nel 2002), agricultural production, or mining (Wilson 2001). Some of these opportunities require temporary migration, while others do not. ${ }^{7}$

6 To construct the asset index, each variable was coded such that increasing values correspond to higher SES and are also effectively given equal weight through rescaling to comparable ranges. The asset values within a group were added and then rescaled to yield a group-specific value in the range 0 to 1 . Finally, for each household, the five group-specific scaled values were summed to yield an overall asset score whose values could range from 0 to 5 (Agincourt HDSS 2011).

7 As in most migration research, questions of endogeneity also arise because of potential correlation between outcome and predictor variables, although none of our predictors exceed a correlation of 0.21 with the household count of temporary outmigrants. Correlations with the count of temporary migrants that exceed 0.10 include those for asset index (0.19), average household education (0.21), and proportion male household members male $(0.13)$, elderly, $(-0.17)$, and in the labor force (0.10). Tests of the impact of specific predictors on the estimations suggest no substantial change in estimation results or errors. 
Natural capital, recent change. Our central measure of natural capital, described above, reflects mean natural resource availability for the three years (2005-2007) before the migration outcome (2007). Since recent shifts in availability may confound the impact of this measure, we also include an indicator of recent change in natural resource availability. In general, the study site experienced a slight increase in "greenness" during 2005-2007. To account for spatial variation in this upward trend, we include a measure of "NDVI slope" as a control variable based on the same underlying greenness pixels used for calculating the average NDVI measure. For each pixel in the $2 \mathrm{~km}$ buffer, the slope was computed by simply fitting a regression line through the NDVI values of the three years.

\section{$4 \quad$ Methods}

The modeling process includes "global" estimates across the entire study site as well as "local" village-scale models, allowing for contrast across the estimated coefficients. We also focus on interaction terms, allowing the effect of all sociodemographic capital variables to vary by a household's mean NDVI, 2005-2007.

\section{Global and Local Village-Scale Modeling}

We compute Poisson Generalized Linear Models (GLM) (McCullagh/Nelder 1989) of temporary household migration using the full set of predictive variables: the primary environmental predictor variable (natural capital: NDVI mean), livelihood capital secondary predictors/controls (human, physical, and financial capitals, and change in natural capital [slope]), and interactions between NDVI mean and the secondary predictors/controls. ${ }^{8}$ The global model has the form

$$
\begin{aligned}
& \eta_{i}=\log _{e}\left(\mu_{i} / \varphi_{i}\right) \\
& \eta_{i}=\beta_{0}+\beta_{1}\left(X_{1 i}\right)+\ldots+\beta_{J}\left(X_{J i}\right)
\end{aligned}
$$

where $\log ()$ represents the link function, the natural logarithm, to transform the outcome variable $\eta_{i j}$ to linearity based on the set of secondary predictors, $\mu_{i j}$ indicates the predicted counts of migrants in household $i$, and $\beta_{0}$ constitutes the intercept (mean log migrant count), while $\beta_{1-J}$ are the regression coefficients of the central predictor variable (NDVI mean), secondary predictors/control variables, and interactions between the environmental predictor and secondary predictors $X_{1 i \text { to }} X_{J i}$.

Since households vary in size, a measure of per-capita migrants is a more objective way of representing the outcome variable than an absolute number. We therefore use household size $\varphi_{i}$ as an offset to convert the number of migrants in house-

8 Poisson models have been successfully applied in a variety of models with count-dependent variables (e.g., Boyle/Flowerdew 1993; Congdon 1993; Leyk et al. 2012). 
hold $i$ to the rate of migrants per household member. To avoid overdispersion, we tested whether the variance equaled the mean of the values - a fundamental assumption for Poisson distributions.

We computed household-level Poisson GLMs for the study site as a whole - the global model - as well as for each village individually. At the local scale, we ran 21 village-scale models. Table 3 summarizes these village-scale results by simply indicating the number of positive and negative statistically significant coefficient estimates across the 21 villages for the NDVI mean measure and each secondary predictor/control. To present specific coefficient estimates at the local scale, we chose four illustrative villages for the presentation of the GLM village-scale results as contrasted with the global model (Table 2). The chosen villages represent the west-east gradient of natural capital within communal lands. Finally, we mapped model coefficients (and their significance levels) at the village scale to represent both the coefficients for NDVI mean (Fig. 3) and the most substantive and statistically significant interaction terms between NDVI and the secondary predictors (Fig. 4).

\section{$5 \quad$ Results}

\subsection{Global Model Estimates}

A key finding is that, considering the Agincourt study site as a whole, the level of natural resource availability (2005-2007) within a household's $2 \mathrm{~km}$ buffer is positively associated with temporary outmigration (2007) - offering support for the "environmental surplus" hypothesis. The estimated coefficient is statistically significant at the 0.01 level, net of the suite of secondary migration predictors within the models. The NDVI slope, 2005-2007, exhibits a positive association with temporary outmigration as well, suggesting that households with higher (and increasing) levels of natural capital are more likely to send temporary migrants.

Virtually all of the secondary predictors obtain statistical significance (with the exception of prime age mortality), no doubt partly due to the relatively large number of observations. In line with previous research, human capital and other forms of assets are important correlates of temporary migration. Households with relatively higher human capital in the form of overall higher education are more likely to have sent a temporary migrant, while such migration was less likely in households with lower levels of human capital in the form of more members of pension age. Temporary migration was also more common among households with more employed members, testifying to the importance of employment as a foundation for fueling migration as a further diversification strategy. Recall that the pairwise correlation between household temporary migration and proportion employed is 0.01 , lessening concerns of endogeneity between migration and employment measures. In addition, the findings suggest that households with a larger proportion of male members and those with higher overall wealth levels/asset position are more likely to have sent a member elsewhere. 


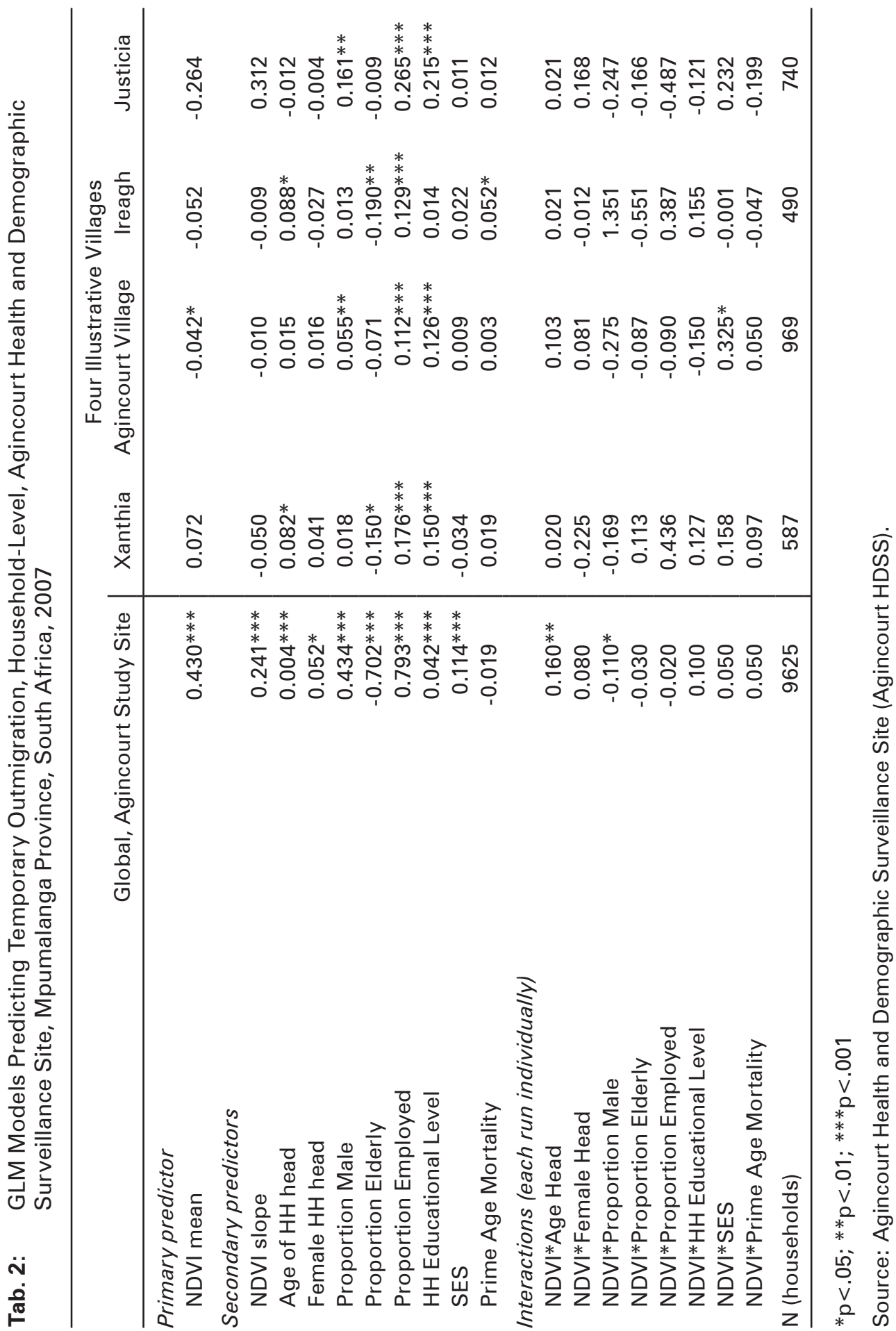


At the global geographic scale, interactions are explored to offer insights on the types of households potentially able to tap into natural capital to fuel temporary migration - yet only two reach statistical significance. The positive estimated effect of NDVI mean on temporary outmigration is magnified for relatively old households as well as those with proportionately fewer men (likely because male members migrated). In this way, the results may suggest that natural capital enables migration by offering livelihood diversification strategies particularly for households with higher levels of human capital in the form of age and male members.

\subsection{Village-Scale Model Estimates}

The Poisson GLM coefficient estimates by village suggest that the processes indicated by the global models operate quite differently at more local scales - which we suggest reflects operational scale sensitivity. Table 3 summarizes village-scale results and illustrates that natural resource availability displays a range of effects, only some of which reach statistical significance. Figure 3 maps the substantively and statistically strongest effects of NDVI mean by village; statistical significance is represented by hatching. In two villages (Kildare A \#11 and Kildare B \#13), consistent with the global estimates, the coefficients reflect a positive, statistically significant association between temporary outmigration and natural resource availability, net of the control variables. Yet in two other villages, the opposite association emerges. In the villages of Agincourt (\#2) and Newington (\#4), a negative, temporary outmigration exhibits a negative, statistically significant association with natural resource availability. Interestingly, these latter villages (in which lower levels of natural capital constrains migration) tend to have relatively high levels of resource availability in general and are on the study site's northern edge, proximate to roads leading to slightly larger neighboring towns (e.g. Thulamahashe, $\sim 11,000$ residents). Here, the potential exists for households to make use of local natural resources as livelihood strategies while also tapping into the market and/or employment potential of nearby communities without necessarily engaging in migration. On the other hand, the villages in which NDVI facilitates migration (Kildare A and B) tend to be in the study site's southeastern corner, more distant from larger neighboring towns and bounded by fenced game reserves. These villages have relatively low levels of resource availability in general while also being further from larger-scale markets and other employment opportunities. In this way, within these resource-poor contexts, households with relatively higher levels of proximate natural capital may be engaging those resources as well as temporary migration as livelihood strategies.

However, in 17 of the 21 villages (81 percent), the influence of natural resource availability on temporary migration did not reach statistical significance net of the other included secondary predictors/controls (see Table 3) - a result quite different from the positive, statistically significant effect of NDVI at the global scale. Overall, a far less consistent migration-environment narrative emerges when using village boundaries to define study areas.

On the secondary predictor/control variables, at the village scale the most consistent positive predictors of temporary outmigration include measures of human 
Tab. 3: $\quad$ Summary of Village-Level Coefficients Predicting Temporary Outmigration at the Household-Level, Agincourt Health and Demographic Surveillance Site, Mpumalanga Province, South Africa, 2007

\begin{tabular}{lccc}
\hline & Positive sig. & Negative sig. & Not sig. \\
\hline $\begin{array}{l}\text { Primary Predictor } \\
\text { NDVI mean }\end{array}$ & 2 & 2 & 17 \\
Secondary Predictors & & & \\
$\quad$ NDVI slope & 1 & 2 & 18 \\
Age of HH head & 2 & 0 & 19 \\
Female HH head & 0 & 0 & 21 \\
Proportion Male & 8 & 0 & 13 \\
Proportion Elderly & 0 & 6 & 15 \\
Proportion Employed & 18 & 0 & 3 \\
HH Educational Level & 9 & 0 & 12 \\
SES & 3 & 2 & 16 \\
Prime age mortality & 1 & 1 & 19 \\
\hline
\end{tabular}

Source: Agincourt Health and Demographic Surveillance Site (Agincourt HDSS).

capital such as household proportion employed (significant in 18 villages), level of education (significant in 9 villages), and the male proportion (significant in 8 villages). On the other hand, households with relatively more elderly members are consistently less likely to send temporary migrants (significant in 6 villages). Household age composition, female headship, and mortality experience exhibit virtually no association with migration at the village scale (significant in no more than 2 of the 21 villages).

Interaction terms at the village scale allow us to dive deeper into the mechanisms potentially underlying village-scale variation in the migration-environment association. Figure 4 maps the substantively and statistically strongest interactions with NDVI mean, by village. Statistical significance is again represented by hatching.

The lack of predictive power among NDVI interactions at the village-scale is notable. Among the eight sociodemographic variables combined with NDVI to predict temporary outmigration across the 21 included villages $(21 * 8=168$ interactions, not shown), only three (1.7 percent) reached statistical significance, and no distinct patterns emerged.

Households in Agincourt (Village \#2) have relatively high access to natural resources and the probability of temporary outmigration exhibits a significant positive interaction with the asset index (see Table 2). On the other hand, households in Rholane (village \#15) have relatively low access to natural resources and they exhibit the same pattern - a significant positive interaction between the asset index and NDVI as related to temporary outmigration (not shown). This interaction sug- 
Fig. 3: NDVI coefficient estimates predicting temporary outmigration by household, village-level models, Agincourt Health and Demographic Surveillance Site, Mpumalanga Province, South Africa

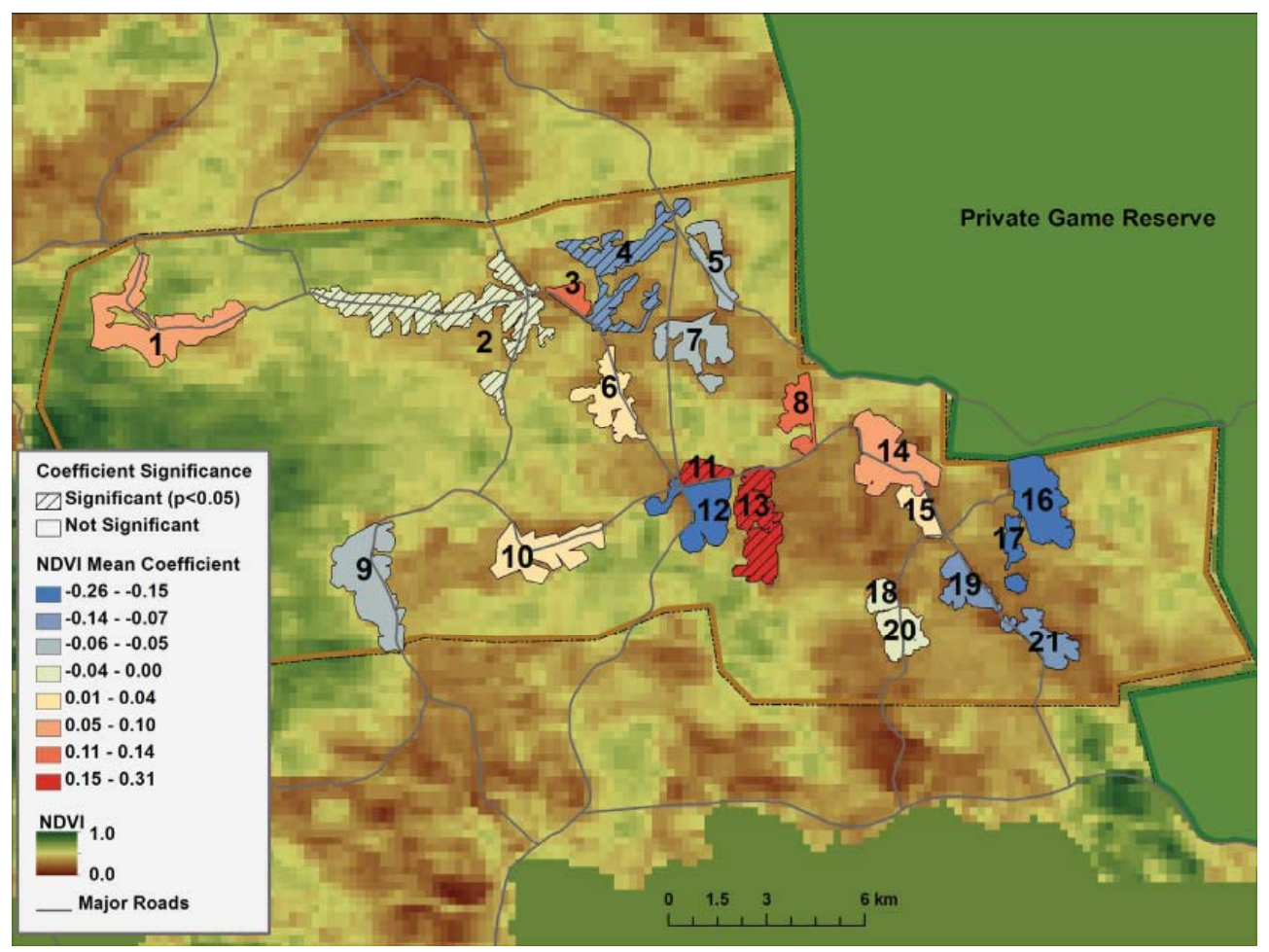

Source: own design

gests that natural capital may fuel migration particularly for those households that already have diverse and stable livelihoods - even in natural resource-poor settings.

Interestingly, households in Justicia B (village \#17) exhibit a strong negative interaction between the proportion of elderly household members (the dependency measure), natural capital, and temporary outmigration. This village has particularly low levels of natural resources given its proximity to private, fenced game reserves. In this natural resource-poor village, monthly pensions, albeit low levels of income, may provide sufficient security to constrain temporary migration. Another interpretation could relate to care-giving, as more elderly household members may suggest others have caregiving responsibilities, also constraining migration. 
Fig. 4: Largest Standardized Coefficients for Interactions between NDVI and Secondary Predictors, Village-level Models, Agincourt Health and Demographic Surveillance Site, Mpumalanga Province, South Africa ${ }^{1}$

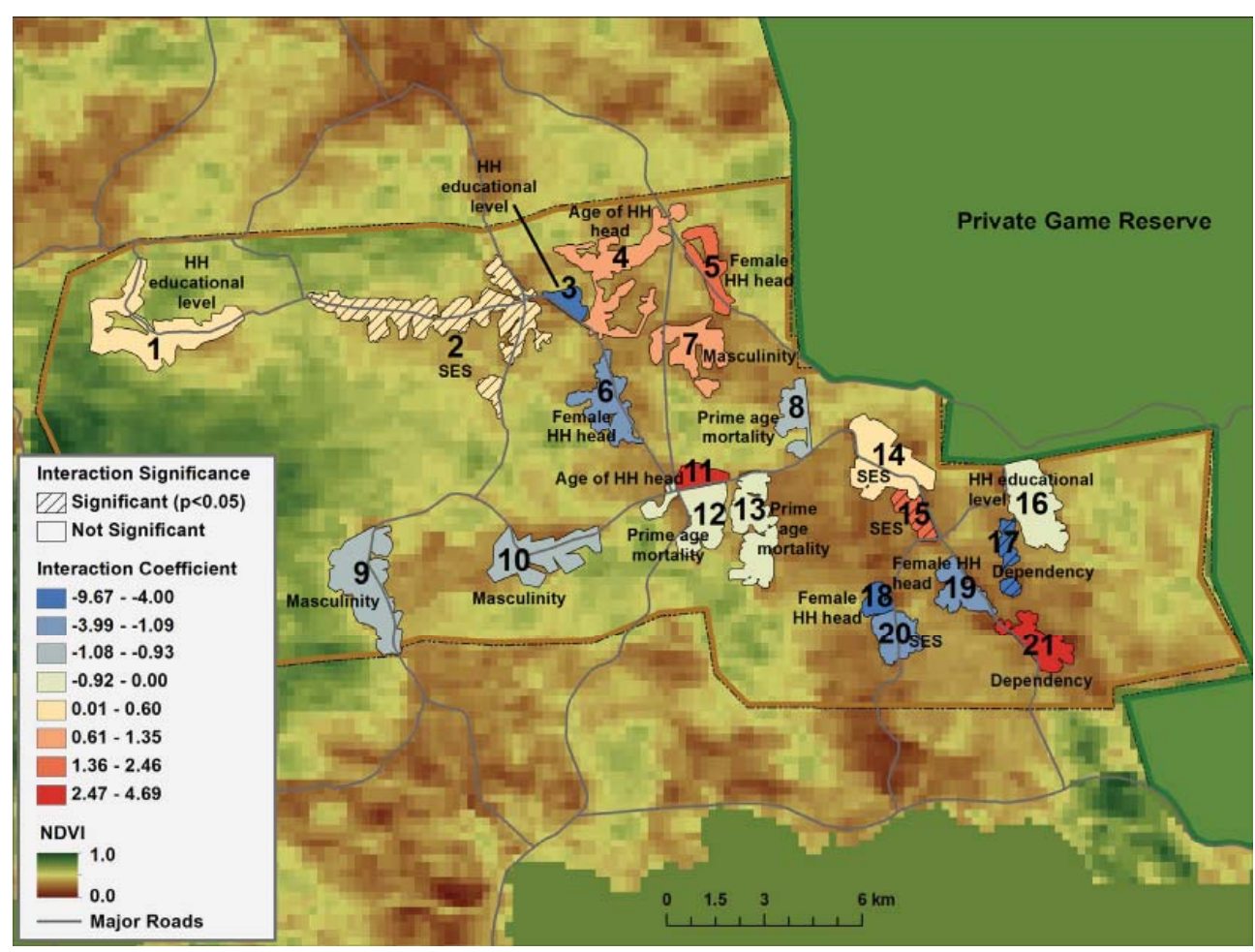

1 “Dependency” = proportion elderly

Source: own design

\section{Conclusion}

The results for both the global and local scales offer multi-faceted contributions to the literature on migration-environment connections, particularly the literature on temporary migration as a livelihood strategy. In rural South Africa, we find support for the "environmental surplus" hypothesis in that households experiencing less environmental stress or scarcity are more likely to send temporary migrants. Such findings stand in contrast to the large flows of refugees converging upon Europe, who are often fleeing from socio-political pressures potentially exacerbated by environmental scarcity. Yet an important distinction is relevant - most migrants from our rural South Africa study site are moving within South Africa and often doing so as a voluntary livelihood strategy. In contrast, the current refugee crisis faced by Europe is fueled by a complex mix of conflict, impoverishment, desperation and environmental challenges - and such movement entails crossing international boundaries. 
Still, our finding of "environmental surplus" migration parallels prior work in Ecuador where migration was facilitated by more productive agricultural lands (Gray 2010). In rural South Africa, households rely heavily on natural resources for both daily sustenance as well as materials for products sold at market (e.g. Ofoegbu et al. 2016). In this way, access to natural capital may provide a safety net of sorts, from which livelihoods may be further diversified - including through temporary migration. The safety net function of local resources has been demonstrated in other research in the Agincourt HDSS setting focused on household coping strategies in the face of adult mortality (Hunter et al. 2007).

Our results in support of the "environmental surplus" hypothesis are usefully considered within the Sustainable Livelihoods Framework in that natural capital intersects with human capital to shape the use of migration as a livelihood strategy. Importantly, however, the results also are distinct from those finding migration associated with the push of "environmental scarcity", as evidenced in settings such as Burkina Faso and Ghana (Henry et al. 2004; Van der Geest 2011).

Our global results of temporary migration linked with "surplus" contributes to the many empirical studies that have been added to the migration-environment literature over the past several years, fueled in part by public and policy concern with the potential for climate change to spur migration by increasing livelihood vulnerability. Indeed, some speculation has been made as to the European refugee crisis being, at least in part, related to climate pressures (e.g., Brzoska/Fröhlich 2016). Such concern certainly warrants intensified scientific inquiry with the aim of ultimately generating conclusions about the connection between migration and environmental conditions/change. Even so, the research presented here also yields a cautionary tale.

The coefficient estimates yielded from the analysis of all Agincourt HDSS households combined may not best reflect the optimal geographic scale to investigate the household-level process under study. In this setting, migration is typically a household-level decision (Collinson et al. 2006). Furthermore, since 85.4 percent of Agincourt households do not own a car, it is likely that the opportunities and constraints within the local village setting may particularly influence livelihood strategies. As such, we tested differences in coefficient estimates across geographic scales to better understand how the migration-environment connection might differentially unfold if the study area is partitioned into individual administrative units.

Differences do unfold. At the village scale, the models identify two villages in which households exhibit a particularly strong positive association between local natural capital and temporary outmigration - where households with higher levels of natural resources within a $2 \mathrm{~km}$ buffer of the homestead were more likely to have sent a temporary migrant within the past year - a finding in line with the overall results from the global model. Even so, the local models also identified two villages with the opposite association - where households with lower levels of natural resources were more likely to have sent a temporary migrant within the past year. Natural capital's negative association with temporary outmigration is intensified for households in resource-poor regions and with access to elderly pensions. 
The incongruent results across models fit to different geographic scales (or geographic extents) leave researchers with a puzzle; and although we raise the question of operational scale sensitivity - we do not propose to have an answer yet. Unlike the ecological fallacy, the example presented here has retained the household as the analytical unit and it is, therefore, justifiable to interpret the coefficients as related to the household level. Unlike the modifiable area unit problem (MAUP), our models do not operate at aggregate units of different size and shape. Instead, we have simply shifted the boundaries of the study areas, focusing first on all Agincourt HDSS households together (global) and then on distinct clusters of households as defined by village borders.

Models fit to each individual village show high levels of predictive power (Leyk et al. 2012) and thus provide an objective picture of existing (or non-existing) relationships. The distinction between scales results from variation in the statistical distributions of incorporated variables due to the different boundaries and, therefore, different study populations. The global model masks associations that are apparent when using statistical distributions as defined by village scale boundaries, yet the village scale analyses do not allow for identification of broader scale migration-environment associations that more generally characterize the entire Agincourt HDSS.

Given this high scale sensitivity, the question remains: what represents a "meaningful" geographic scale to model migration-environment associations? We offer the unsatisfactory answer that "it depends". On the one hand, researchers often aim to identify overarching conclusions that represent broad patterns in migration-environment connections. In this case, the global model, covering a broader geographic region, offers an understanding of how this linkage operates at the scale of a small region. Yet, since households represent the locus of migration decision-making, village scale models may represent a more appropriate vantage point since these decisions are likely influenced by localized livelihood options (including availability of natural capital) especially given low levels of vehicle ownership. In addition, examination of goodness-of-fit measures suggest the village-scale models offer better prediction of household-level migration as contrasted with the global, regional estimates (Leyk et al. 2012).

In summary, our results suggest that, generally, natural resource security provides a foundation from which households may engage in temporary livelihood migration from rural South Africa. Even so, in some highly localized village settings, local scarcity also fuels temporary livelihood migration. Of central importance in future research will be the investigation of temporal variation in the migration-environment connection and, in particular, under conditions of more chronic and/or prevalent environmental change across the villages in rural South Africa's Agincourt Health and Demographic Surveillance Site.

\section{Acknowledgements}

Supported by NIH R03 HD061428, "Environmental Variability, Migration, and Rural Livelihoods". This research has also benefited from the NICHD-funded University of Colorado Population Center (Project 2P2CHD066613-06) for research, administra- 
tive, and computing support. The content is solely the responsibility of the authors and does not necessarily represent the official views of the CUPC, NIH, or NICHD. This work was also indirectly supported by the Wellcome Trust (grant 085477/Z/08/Z) through its support of the Agincourt Health and Demographic Surveillance System.

\section{References}

Agincourt HDSS (Agincourt Health and Socio-demographic Surveillance System) 2011: Agincourt Health and Population Unit: Data Definitions. Johannesburg. South Africa: University of the Witwatersrand [http://www.agincourt.co.za/DataSection/DataDocumentation.htm, 19.09.2011].

Aksakal, Mustafa; Schmidt, Kerstin 2015: Migration and Social Protection as Adaptation in Response to Climate-Related Stressors: The case of Zacatecas in Mexico. In: Hillmann, Felicitas et al. (Eds): Environmental Change, Adaptation and Migration: Bringing in the Region. Hampshire: Palgrave Macmillan: 80-97 [doi: 10.1057/9781137538918_5].

Anselin, Luc 1995: Local Indicators of Spatial Association - LISA. In: Geographical Analysis 27,2: 93-115 [doi: 10.1111/j.1538-4632.1995.tb00338.x].

Barbieri, Alisson F.; Carr, David L. 2005: Gender-Specific Out-Migration, Deforestation and Urbanization in the Ecuadorian Amazon. In: Global and Planetary Change 47,2: 99 110 [doi: 10.1016/j.gloplacha.2004.10.005].

Bardsley, Douglas K.; Hugo, Graeme J. 2010: Migration and Climate Change: Examining Thresholds of Change to Guide Effective Adaptation Decision-making. In: Population and Environment 32,2-3: 238-262 [doi: 10.1007/s11111-010-0126-9].

Beine, Michel; Parsons, Christopher 2015: Climatic factors as determinants of international migration. In: The Scandinavian Journal of Economics 117,2: 723-767 [doi: 10.1111/sjoe.12098].

Bhatta, Gopal Datt; Aggarwal, Pramod Kumar 2016: Coping with weather adversity and adaptation to climatic variability: a cross-country study of smallholder farmers in South Asia. In: Climate and Development 8,2: 145-157 [doi: 10.1080/17565529.2015.1016883].

Bilsborrow, Richard E. 2002: Migration, Population Change and the Rural Environment. In: ECSP Report. Woodrow Wilson International Center for Scholars, Environmental Change and Security Project. Issue 8: 69-94 [https://www.wilsoncenter.org/sites/default/files/ACF80.pdf].

Bilsborrow, Richard E. 2009: Collecting data on the migration-environment nexus. In: Laczko, Frank; Aghazarm, Christine (Eds.): Migration, Environment and Climate Change: Assessing the Evidence. Geneva: International Organization for Migration: 115-196.

Binns, Tony; Nel, Etienne 2002: Tourism as a Local Development Strategy in South Africa. In: The Geographical Journal 168: 235-247 [doi: 10.1111/1475-4959.00051].

Black, Richard et al. 2011: The Effect of Environmental Change on Human Migration. In: Global Environmental Change 21: S3-S11 [doi: 10.1016/j.gloenvcha.2011.10.001].

Bohara, Alok K.; Krieg, Randall G. 1996: A Zero-Inflated Poisson Model of Migration Frequency. In: International Regional Review 19,3: 211-222 [doi: 10.1177/ 016001769601900302].

Boyle, Paul J.; Flowerdew, Robin 1993: Modelling sparse interaction matrices: interward migration in Hereford and Worcester, and the underdispersion problem. In: Environment and Planning 25,8: 1201-1209 [doi: 10.1068/a251201]. 
Brzoska, Michael; Fröhlich, Christiane 2016: Climate change, migration and violent conflict: vulnerabilities, pathways and adaptation strategies. In: Migration and Development 5,2: 190-210 [doi: 10.1080/21632324.2015.1022973].

Carr, David L.; Pan, William K.Y.; Bilsborrow Richard E. 2006: Declining Fertility on the Frontier: The Ecuadorian Amazon. In: Population and Environment 28,1: 17-39 [doi: 10.1007/s11111-007-0032-y].

Cohen, Jeffrey H. 2004: The Culture of Migration in Southern Mexico. Austin: University of Texas Press.

Collinson, Mark A. 2010: Striving Against Adversity: The Dynamics of Migration, Health and Poverty in Rural South Africa. In: Global Health Action 3,1: 5080 [doi: 10.3402/gha. v3i0.5080].

Collinson, Mark A. et al. 2006: Highly Prevalent Circular Migration: Households, Mobility and Economic Status in Rural South Africa. In: Tienda, Marta et al. (Eds.): Africans on the Move: Migration in Comparative Perspective. Johannesburg: Wits University Press: 194-216.

Congdon, Peter 1993: Approaches to modelling overdispersion in the analysis of migration. In: Environment and Planning 25,10: 1481-1510 [doi: 10.1068/a251481].

de Sherbinin, Alex et al. 2008: Rural Household Demographics, Livelihoods and the Environment. In: Global Environmental Change 18,1: 38-53 [doi: 10.1016/j.gloenvcha.2007.05.005].

Debnath, Priyanka 2015: Climate change-induced migration and post-disaster remittance responses through a gender lens. In: Hillmann, Felicitas et al. (Eds.): Environmental Change, Adaptation and Migration: Bringing in the Region. Hampshire: Palgrave Macmillan: 186-199.

Edmeades, Jeffrey 2008: The Legacies of Context: Past and Present Influences on Contraceptive Choice in Nang Rong, Thailand. In: Demography 45,2: 283-302 [doi: 10.1353/dem.0.0004]

Entwisle, Barbara 2007: Putting People Into Place. In: Demography 44,4: 687-703 [doi: 10.1353/dem.2007.0045].

Etzold, Benjamin et al. 2014: Clouds gather in the sky, but no rain falls. Vulnerability to rainfall variability and food insecurity in Northern Bangladesh and its effects on migration. In: Climate and Development 6,1: 18-27 [doi: 10.1080/17565529.2013.833078].

Fisher, Jolene T. et al. 2011: Human-Modified Landscapes: Patterns of Fine-Scale Woody Vegetation Structure in Communal Savannah Rangelands. In: Environmental Conservation 39,1: 72-82 [doi: 10.1017/S0376892911000592].

Foody, Giles M. et al. 2001: Mapping the Biomass of Bornean Tropical Rain Forest From Remotely Sensed Data. In: Global Ecology and Biogeography 10,4: 379-387 [doi: 10.1046/j.1466-822X.2001.00248.x].

Fotheringham, A. Steward 1997: Trends in Quantitative Methods I: Stressing the Local. In: Progress in Human Geography 21,1: 88-96 [doi: 10.1191/030913297676693207].

Fotheringham, A. Steward; Brundson, Chris 1999: Local Forms of Spatial Analysis. In: Geographical Analysis 31,4: 340-358 [doi: 10.1111/j.1538-4632.1999.tb00989.x].

Fussell, Elizabeth; Hunter, Lori M.; Gray, Clark L. 2014: Measuring the environmental dimensions of human migration: The demographer's toolkit. In: Global Environmental Change 28: 182-191 [doi: 10.1016/j.gloenvcha.2014.07.001].

Giannecchini, Monica; Twine, Wayne; Vogel, Coleen 2007: Land-Cover Change and Human-Environment Interactions in a Rural Cultural Landscape in South Africa. In: Geographical Journal 173,1: 26-42 [doi: 10.1111/j.1475-4959.2007.00227.x]. 
Gray, Clark L. 2010: Gender, Natural Capital, and Migration in the Southern Ecuadorian Andes. In: Environment and Planning 42,3: 678-696 [doi: 10.1068/a42170].

Gray, Clark L.; Bilsborrow, Richard 2013: Environmental Influences on Human Migration in Rural Ecuador. In: Demography 50,4: 1217-1241 [doi: 10.1007/s13524-012-0192-y].

Gray, Clark L.; Mueller, Valerie 2012a: Natural Disasters and Population Mobility in Rural Bangladesh. In: Proceedings of the National Academy of Sciences 109,16: 6000-6005 [doi: 10.1073/pnas.1115944109].

Gray, Clark L.; Mueller, Valerie 2012b: Drought and Population Mobility in Rural Ethiopia. In: World Development 40,1: 134-145 [doi: 10.1016/j.worlddev.2011.05.023].

Gray, Clark L.; Wise, Erika 2016: Country-specific effects of climate variability on human migration. In: Climatic change 135,3-4: 555-568 [doi: 10.1007/s10584-015-1592-y].

Gray, Clark L. et al. 2008: Indigenous Land Use in the Ecuadorian Amazon: A Crosscultural and Multilevel Analysis. In: Human Ecology 36,1: 97-109 [doi: 10.1007/s10745007-9141-6].

Greenland, Sander; Morgenstern, Hal 1989: Ecological Bias, Confounding, and Effect Modification. In: International Journal of Epidemiology 18: 269-274.

Hargreaves, James R. et al. 2004: Childhood Mortality Among Former Mozambican Refugees and Their Hosts in Rural South Africa. In: International Journal of Epidemiology 33,6: 1271-1278 [doi: 10.1093/ije/dyh257].

Henry, Sabine; Schoumaker, Bruno; Beauchemin, Cris 2004: The Impact of Rainfall on the First Out-Migration: A Multi-Level Event-History Analysis in Burkina Faso. In: Population and Environment 25,5: 423-460 [doi: 10.1023/B:POEN.0000036928.17696.e8].

Hillmann, Felicitas et al. (Eds) 2015: Environmental Change, Adaptation and Migration: Bringing in the Region. Hampshire: Palgrave Macmillan.

Huete, Alfredo et al. 2002: Overview of the Radiometric and Biophysical Performance of the MODIS Vegetation Indices. In: Remote Sensing of Environment 83,1-2: 195-213 [doi: 10.1016/S0034-4257(02)00096-2].

Hunter, Lori M.; David, Emmanuel 2011: Climate Change and Migration: Considering Gender Dimensions. In: Piguet, Etienne; de Guchteneire, Paul; Pecoud, Antoine (Eds): Climate Change and Migration. Cambridge: UNESCO Publishing and Cambridge University Press.

Hunter, Lori M. et al. 2014: Rural outmigration, natural capital, and livelihoods in South Africa. In: Population, space and place 20,5: 402-420 [doi: 10.1002/psp.1776].

Hunter, Lori M.; Luna, Jessie K.; Norton, Rachel M. 2015: Environmental Dimensions of Migration. In: Annual Review of Sociology 41: 377-397 [doi: 10.1146/annurevsoc-073014-112223].

Hunter, Lori M.; Murray, Sheena; Riosmena, Fernando 2013: Rainfall Patterns and U.S. Migration from Rural Mexico. In: International Migration Review 47,-4: 874-909 [doi: 10.1111/imre.12051].

Hunter, Lori M.; Twine, Wayne; Johnson, Aaron 2011: Adult Mortality and Natural Resource Use in Rural South Africa: Evidence From the Agincourt Health and Demographic Surveillance Site. In: Society \& Natural Resources 24,3: 256-275 [doi: 10.1080/08941920903443327].

Hunter, Lori M.; Twine, Wayne; Patterson, Laura 2007: "Locusts Are Now Our Beef": Adult Mortality and Household Dietary Use of Local Environmental Resources in rural South Africa. In: Scandinavian Journal of Public Health 35,69: 165-174 [doi: 10.1080/14034950701356385]. 
Jülich, Sebastian 2011: Drought Triggered Temporary Migration in an East Indian Village. In: International Migration 49,s1: e189-e199 [doi: 10.1111/j.1468-2435.2010.00655.x].

Kandel, William; Massey, Douglas S. 2002: The culture of Mexican migration: A theoretical and empirical analysis. In: Social forces 80,2: 981-1004 [doi: 10.1353/sof.2002.0009].

Kniveton, Dominic R.; Smith, Christopher D.; Black, Richard 2012: Emerging Migration Flows in a Changing Climate in Dryland Africa. In: Nature Climate Change 2: 444-447 [doi: 10.1038/nclimate1447].

Kniveton, Dominic et al. 2008: Climate change and migration: Improving methodologies to estimate flows. IOM Migration Research Series Paper No. 33. Geneva/Switzerland: International Organisation for Migration (IOM).

Lam, Nina S.; Quattrochi, Dale A. 1992: On the issues of scale, resolution, and fractal analysis in the mapping sciences. In: The Professional Geographer 44,1: 88-98 [doi: 10.1111/j.0033-0124.1992.00088.x].

Leyk, Stefan et al. 2012: Spatially and Temporally Varying Associations Between Temporary Outmigration and Natural Resource Availability in Resource-Dependent Rural Communities in South Africa: A Modeling Framework. In: Applied Geography 34: 559 568 [doi: 10.1016/j.apgeog.2012.02.009].

MacLaurin, Galen; Leyk, Stefan; Hunter, Lori M. 2015: Understanding the impacts of aggregation while accounting for spatial non-stationarity: The case of migration models. In: Transactions in GIS 19,6: 877-895 [doi: 10.1111/tgis.12134].

Madhavan, Sangeetha; Schatz, Enid; Clark, Benjamin 2009: Effect of HIV/AIDS-Related Mortality on Household Dependency Ratios in Rural South Africa, 2000-2005. In: Population Studies 63,1: 37-51 [doi: 10.1080/00324720802592784].

Madubansi, Mainza; Shackleton, Charlie M. 2007: Changes in fuelwood use and selection following electrification in the Bushbuckridge lowveld, South Africa. In: Journal of Environmental Management 83,4: 416-426 [doi: 10.1016/j.jenvman.2006.03.014].

Massey, Douglas S. et al. 1993: Theories of International Migration - A Review and Appraisal. In: Population and Development Review 19,3: 431-466 [doi: 10.2307/2938462].

Massey, Douglas S.; Axinn, William G.; Ghimire, Dirgha J. 2010: Environmental Change and Out-Migration: Evidence from Nepal. In: Population and Environment 32,2-3: 109136 [doi: 10.1007/s11111-010-0119-8].

Mberu, Blessing Uchenna 2006: Internal Migration and Household Living Conditions in Ethiopia. In: Demographic Research 14: 509-539 [doi: 10.4054/DemRes.2006.14.21].

McCullagh, Peter; Nelder, John A. 1989: Generalized Linear Models. Boca Raton: CRC Press.

McLeman, Robert 2013a: Climate and Human Migration: Past Experiences, Future Challenges. New York: Cambridge University Press.

McLeman, Robert 2013b: Developments in modelling of climate change-related migration. In: Climatic Change 117,3: 599-611 [doi: 10.1007/s10584-012-0578-2].

McLeman, Robert; Hunter, Lori M. 2010: Migration in the Context of Vulnerability and Adaptation to Climate Change: Insights from Analogues. In: WIREs Climate Change 1,3: 450-461 [doi: 10.1002/wcc.51].

Montgomery, Mark R. et al. 2000: Measuring Living Standards with Proxy Variables. In: Demography 37,2: 155-174 [doi: 10.2307/2648118].

Moran, Patrick A.P. 1950: Notes on Continuous Stochastic Phenomena. In: Biometrika 37: 17-33. 
Morrissey, James 2012: Rethinking the 'debate on environmental refugees': from 'maximilists and minimalists' to 'proponents and critics'. In: Journal of Political Ecology. 19: 36-49.

Mueller, Valerie; Gray, Clark; Kosec, Katrina 2014: Heat stress increases long-term human migration in rural Pakistan. In: Nature climate change 4,3: 182-185 [doi: 10.1038/ nclimate2103].

Mutanga, Onisimo; Skidmore, Andrew K. 2004a: Narrow Band Vegetation Indices Overcome the Saturation Problem in Biomass Estimation. In: International Journal of Remote Sensing 25,19: 3999-4014 [doi: 10.1080/01431160310001654923].

Mutanga, Onisimo; Skidmore, Andrew K. 2004b: Merging Double Sampling with Remote Sensing for a Rapid Estimation of Fuelwood. In: Geocarto International 19,4: 49-55 [doi: 10.1080/10106040408542327].

Myers, Norman 2002: Environmental refugees: a growing phenomenon of the $21^{\text {st }}$ century. In: Philosophical Transactions of the Royal Society B. 357,1420: 609-613 [doi: 10.1098/rstb.2001.0953].

Nawrotzki, Raphael J.; DeWaard, Jack 2016: Climate shocks and the timing of migration from Mexico. In: Population and Environment 38,1: 1-29 [doi: 10.1007/s11111-0160255-x].

Nawrotzki, Raphael J.; Hunter, Lori M.; Dickinson, Thomas W. 2012: Rural Livelihoods and Access to Natural Capital: Differences Between Migrants and Non-Migrants in Madagascar. In: Demographic Research 26,24: 661-700 [doi: 10.4054/DemRes.2012.26.24].

Nawrotzki, Raphael J. et al. 2015: Climate change as a migration driver from rural and urban Mexico. In: Environmental Research Letters 10,11: 114023 [doi: 10.1088/17489326/10/11/114023].

Nawrotzki, Raphael J. et al. 2015: Amplification or suppression: Social networks and the climate change - migration association in rural Mexico. In: Global Environmental Change 35: 463-474 [doi: 10.1016/j.gloenvcha.2015.09.002].

Nawrotzki, Raphael J.; Riosmena, Fernando; Hunter, Lori M. 2013: Do Rainfall Deficits Predict U.S.-Bound Migration from Rural Mexico? Evidence from the Mexican Census. In: Population Research and Policy Review 32,1: 129-158 [doi: 10.1007/s11113-0129251-8].

Nawrotzki, Raphael J. et al. 2016: Domestic and International Climate Migration from Rural Mexico. In: Human Ecology 44,6: 687-699 [doi: 10.1007/s10745-016-9859-0].

Nivalainen, Satu 2004: Determinants of Family Migration: Short Moves vs. Long Moves. In: Journal of Population Economics 17,1: 157-175 [doi: 10.1007/s00148-003-0131-8].

Ofoegbu, Chidiebere et al. 2016: Assessing forest-based rural communities' adaptive capacity and coping strategies for climate variability and change: The case of Vhembe district in south Africa. In: Environmental Development 18: 36-51 [doi: 10.1016/j.envdev.2016.03.001].

Openshaw, Stan 1983: The Modifiable Areal Unit Problem. Norwich, UK: Geo Books.

Paumgarten, Fiona; Shackleton, Charlie M. 2011: The Role of Non-Timber Forest Products in Household Coping Strategies in South Africa: The Influence of Household Wealth and Gender. In: Population and Environment 33,1: 108-113 [doi: 10.1007/s11111011-0137-1].

Piguet, Etienne 2010: Linking climate change, environmental degradation, and migration: a methodological overview. In: Wiley Interdisciplinary Reviews: Climate Change 1,4: 517-524 [doi: 10.1002/wcc.54]. 
Piguet, Etienne; Pecoud, Antoine; de Guchteneire, Paul 2011: Migration and Climate Change: An Overview. In: Refugee Survey Quarterly 30,3: 1-23.

Robinson, William S. 1950: Ecological correlations and the behavior of individuals. In: American Sociological Review 15,3: 351-357.

Roerink, Gerbert J. et al. 2003: Assessment of Climate Impact on Vegetation Dynamics by Using Remote Sensing. In: Physics and Chemistry of the Earth 28,1-3: 103-109 [doi: 10.1016/S1474-7065(03)00011-1].

Saenz, Rogelio; Morales, M. Cristina 2006: Demography of Race and Ethnicity. In: Poston, Dudley L.; Micklin, Michael (Eds.): Handbook of Population. New York: Springer 169-208.

Scoones, Ian 1998: Sustainable Rural Livelihoods: A Framework for Analysis. IDS Working Paper 72. Brighton: Institute of Development Studies [http://200.17.236.243/pevs/ Agroecologia/Sustainable\%20Rural\%20Livelihhods-Scoones.pdf, accessed February 2017].

Scoones, lan 2009: Livelihoods perspectives and rural development. In: The Journal of Peasant Studies 36,1: 171-196 [doi: 10.1080/03066150902820503]

Shackleton, Charlie M.; Shackleton, Sheona E. 2000: Direct Use Values of Savanna Resources Harvested from Communal Savannas in the Bushbuckridge Lowveld, South Africa. In: Journal of Tropical Forest Products 6,1: 28-47.

Stark, Oded; Bloom, David E. 1985: The new economics of labor migration. In: The American Economic Review 75,2: 173-178.

Suhrke, Astri 1994: Environmental degradation and population flows. In: Journal of International Affairs 47,2: 473-496.

Taylor, J. Edward 1999: The New Economics of Labour Migration and the Role of Remittances in the Migration Process. In: International Migration 37,1: 63-88 [doi: 10.1111/1468-2435.00066]

Taylor, J. Edward et al. 1996: International Migration and Community Development. In: Population Index 62,3: 397-418 [doi: 10.2307/3645924].

Thiede, Brian; Gray, Clark; Mueller, Valerie 2016: Climate variability and inter-provincial migration in South America, 1970-2011. In: Global Environmental Change 41: 228-240 [doi: 10.1016/j.gloenvcha.2016.10.005].

Thondhlana, Gladman; Vedeld, Pål; Shackleton, Sheona E. 2012: Natural resource use, income and dependence among San and Mier communities bordering Kgalagadi Transfrontier Park, southern Kalahari, South Africa. In: International Journal of Sustainable Development \& World Ecology 19,5: 460-470 [doi: 10.1080/13504509.2012.708908].

Tollman, Stephen M. et al. 1999: The Agincourt Demographic and Health Study - Site Description, Baseline Findings and Implications. In: South African Medical Journal 89,8: 858-864.

Tucker, Compton J. 1979: Red and Photographic Infrared Linear Combinations for Monitoring Vegetation. In: Remote Sensing of Environment 8,2: 127-150 [doi: 10.1016/00344257(79)90013-0].

Twine, Wayne et al. 2003: Consumption and direct-use values of savanna bio-resources used by rural households in Mametja, a semi-arid area of Limpopo province, South Africa. In: South African Journal of Science 99: 467-473.

Van der Geest, Kees 2011: North-South migration in Ghana: what role for the environment? In: International Migration 49,s1: e69-e94 [doi: 10.1111/j.1468-2435.2010.00645.x]. 
Vanwey, Leah K. 2003: Land Ownership as a Determinant of Temporary Migration in Nang Rong, Thailand. In: European Journal of Population 19,2: 121-145 [doi: 10.1023/A:1023307100719].

Vanwey, Leah K.; D'Antona, Álvaro de Oliveira; Bondizio, Eduardo S. 2007: Household Demographic Change and Land Use/Land Cover Change in the Brazilian Amazon. In: Population and Environment 28,3: 163-185 [doi: 10.1007/s11111-007-0040-y].

Waller, Lance A.; Gotway, Carol A. 2004: Applied Spatial Statistics for Public Health Data. Hoboken/ NJ: John Wiley \& Sons.

Wang, Jida; Rich, Paul M.; Price, Kevin P. 2003: Temporal Responses of NDVI to Precipitation and Temperature in the Central Great Plains, USA. In: International Journal of Remote Sensing 24,11: 2345-2364 [doi: 10.1080/01431160210154812].

Wang, Jida et al. 2004: Relations Between NDVI and Tree Productivity in the Central Great Plains. In: International Journal of Remote Sensing 25,16: 3127-3138 [doi: 10.1080/0143116032000160499].

Warner, Koko 2011: Environmental change and migration: methodological considerations from ground-breaking global survey. In: Population \& Environment 33,1: 3-27 [doi: 10.1007/s11111-011-0150-4].

White, Michael J.; Lindstrom, David .P. 2006: Internal Migration. In: Poston, Dudley L.; Micklin, Michael: Handbook of Population. New York: Kluwer Academic Publishers: 311-346

Wilson, Francis 2001: Minerals and Migrants: How the Mining Industry Has Shaped South Africa. In: Daedalus 130,1: 99-121.

Wong, David. 1995: Aggregation Effects in Geo-referenced Data. In: Arlinghaus, Sandra L. (Ed.): Practical Handbook of Spatial Statistics. Boca Raton: CRC Press: 83-106.

Zhou, Liming et al. 2003: Relation Between Interannual Variations in Satellite Measures of Northern Forest Greenness and Climate Between 1982 and 1999. In: Journal of Geophysical Research 108,D1: ACL 3-1-ACL 3-16 [doi: 10.1029/2002JD002510]. 
Prof. Dr. Lori M. Hunter ( $\triangle)$. University of Colorado Boulder, USA. MRC/Wits Rural Public Health and Health Transitions Research Unit (Agincourt), School of Public Health, University of Witwatersrand, South Africa. E-mail: Lori.Hunter@colorado.edu URL: http://www.colorado.edu/ibs/es/hunterl/

Prof. Dr. Stefan Leyk. University of Colorado Boulder, USA.

E-mail: stefan.leyk@colorado.edu

URL: http://www.colorado.edu/geography/stefan-leyk-0

Dr. Galen J. Maclaurin. University of Colorado Boulder, USA.

E-mail: galen.maclaurin@colorado.edu

Dr. Raphael Nawrotzki. University of Colorado Boulder, USA.

E-mail: Raphael.Nawrotzki@colorado.edu

Prof. Dr. Wayne Twine. School of Animal, Plant and Environmental Sciences, University of the Witwatersrand, South Africa. E-mail: Wayne.Twine@wits.ac.za

URL: https://www.wits.ac.za/staff/academic-a-z-listing/t/waynetwinewitsacza/

Prof. Dr. Barend F.N. Erasmus. Global Change Institute, University of the Witwatersrand, South Africa. E-mail: Barend.Erasmus@wits.ac.za

URL: https://www.wits.ac.za/staff/academic-a-z-listing/e/barenderasmuswitsacza/

Dr. Mark Collinson. MRC/Wits Rural Public Health and Health Transitions Research Unit (Agincourt), School of Public Health, University of Witwatersrand, South Africa. Department of Science and Technology/ Medical Research Council, South African Population Research Infrastructure Network (SAPRIN). INDEPTH Network, Ghana. E-mail: Mark@agincourt.co.za

URL: http://www.agincourt.co.za/index.php/about/staff/mark-collinson/ 


\section{Comparative Population Studies}

wWW.comparativepopulationstudies.de

ISSN: 1869-8980 (Print) - 1869-8999 (Internet)

\section{Published by}

Prof. Dr. Norbert F. Schneider

Federal Institute for Population Research D-65180 Wiesbaden / Germany

\section{(cc) BY-SA}

2017

\section{Managing Editor}

Frank Swiaczny

\section{Assistant Managing Editor}

Katrin Schiefer

\section{Copy Editor}

(Selected Articles in German)

Dr. Evelyn Grünheid

\section{Layout}

Beatriz Feiler-Fuchs

E-mail: cpos@bib.bund.de

\section{Scientific Advisory Board}

Paul Gans (Mannheim)

Karsten Hank (Cologne)

Johannes Huinink (Bremen)

Michaela Kreyenfeld (Rostock)

Marc Luy (Vienna)

Notburga Ott (Bochum)

Peter Preisendörfer (Mainz)

Nikola Sander (Groningen)

Zsolt Spéder (Budapest)

\section{Board of Reviewers}

Martin Abraham (Erlangen)

Laura Bernardi (Lausanne)

Hansjörg Bucher (Bonn)

Claudia Diehl (Konstanz)

Andreas Diekmann (Zurich)

Gabriele Doblhammer-Reiter (Rostock)

Jürgen Dorbritz (Wiesbaden)

Anette Eva Fasang (Berlin)

E.-Jürgen Flöthmann (Bielefeld)

Alexia Fürnkranz-Prskawetz (Vienna)

Beat Fux (Salzburg)

Joshua Goldstein (Berkeley)

Sonja Haug (Regensburg)

Hill Kulu (Liverpool)

Aart C. Liefbroer (The Hague)

Kurt Lüscher (Konstanz)

Emma Lundholm (Umeå)

Nadja Milewski (Rostock)

Dimiter Philipov (Vienna)

Roland Rau (Rostock)

Tomáš Sobotka (Vienna)

Jeroen Spijker (Barcelona)

Olivier Thévenon (Paris)

Helga de Valk (Brussels)

Heike Trappe (Rostock)

Michael Wagner (Cologne) 